\title{
AXIAL STIFFNESS OF MULTIWALLED CARBON NANOTUBES AS A FUNCTION OF THE NUMBER OF WALLS
}

\author{
V. ZAVALNIUK
}

PACS 61.48.De, 62.25.-g,

Department of Theoretical Physics, I.I. Mechnikov Odessa National University

(C) 2012

(2, Dvoryanskaya Str., Odessa 65026, Ukraine; e-mail: vzavalnyuk@ onu. edu. ua)

\begin{abstract}
The axial stiffness of multiwalled carbon nanotubes (MWCNTs) is studied as a function of the number of walls and their parameters. It is demonstrated that the axial stiffness is determined only by several external shells (usually $3-5$ and up to 15 for the extremely large nanotubes and high elongations) which is in good agreement with the experimentally observed inverse relation between the radius and the Young modulus (i.e., stiffness) of MWCNTs. Such behavior is a consequence of the van der Waals intershell interaction. An interpolating formula for the MWCNT's actual axial stiffness as a function of the external radius and the elongation of a tube is obtained.
\end{abstract}

\section{Introduction}

The unusual and even sometimes wonderful mechanical properties of carbon nanotubes and their bundles make it possible to use them just now for a wide range of applications. As an example, nanotubes can act as a reinforcement of different materials (plastics, hydrocarbon resins, nanocomposites, etc.), where their extremal bending flexibility and axial stiffness are of great interest $[1-3]$.

It is established that single-walled carbon nanotubes (SWCNTs) can sustain strains larger than $10 \%$ of a tensile deformation prior to the fracture $[4,5]$, and their deformation is completely reversible (i.e., elastic), while they are subjected to strains up to $4 \%$ and even higher [6-9]. A lot of works were devoted to the investigation of elastic properties of SWCNTs and MWCNTs [5, 818]. MWCNTs were thoroughly studied theoretically for a uniform axial stress distribution at both of their ends [19], but this is not the only possible loading type. Apparently in most cases of axial tension, only the external shell of MWCNT is affected by the imposed load, and its internal shells are involved into the considered process only due to the van der Waals intershell interaction (a simple case of such a situation is the deformation of capped MWCNTs or MWCNTs with shells of unequal lengths (see, e.g., Fig. 1)).

It is obvious that, in the case of an uniformly deformed $n$-walled CNT, the intershell distances $\Delta r_{i}=r_{i}-r_{i+1}=$ $(1-\nu \varepsilon) d_{0}$ remain equal. Here, $i$ numbers nanotube's shells begining with the outermost one; $\varepsilon$ is the external shell specific elongation, and $\nu$ is Poisson's ratio of graphene. So, MWCNT's total deformation energy would be simply the sum of the deformation energies of its shells plus a negligible (about 1\%) contribution of van der Waals forces i.e. its Young modulus $Y \approx \sum_{i} Y_{i}$. But when the load is imposed only on the external shell, the distances between other shells are not equal and increase with $i$ (for $\varepsilon>0$ ). Due to the strong nonlinear dependence of the intershell interaction on the intershell distances, the difference in the deformation energies in both mentioned cases for certain specific elongations may be significant and should be studied.

The experimental study showed that the effective Young modulus of MWCNT is inversely proportional

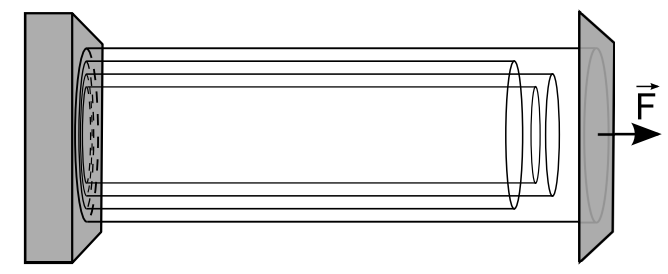

Fig. 1. Deformation of MWCNT with shells of unequal lengths. Imposed force is applied only to the external shell 


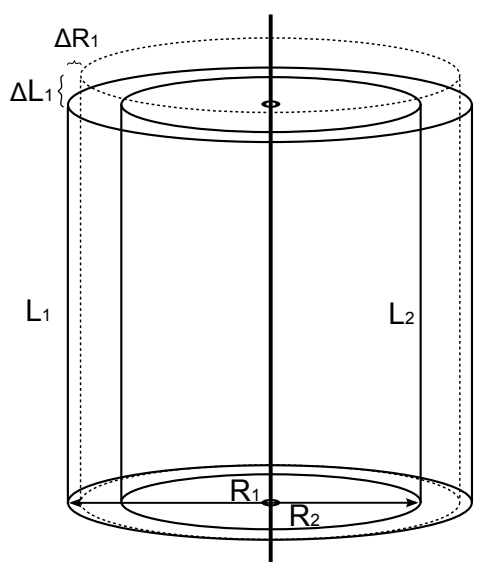

Fig. 2. Definition of the main geometrical parameters of DWCNT

to its radius (for radii in the interval from $4 \mathrm{~nm}$ to 20 $\mathrm{nm}$ ) [20], and such results contradict the assumption about the equal deformations of shells. Some theoretical works also indicated the dependence of the effective Young modulus on the number of wall $[18,21]$, while the other ones showed no dependence on the radius even for SWCNTs [19, 22]. Computer simulations showed that the inner layers of MWCNT can be effectively deformed only through the direct application of tensile or shear forces, but nanotubes with only $2-4$ shells were studied [23].

In this paper, we use the stiffness $k=\frac{F}{\varepsilon L}$ (where $F$ is the imposed force, and $L$ is the nanotube length) instead of the Young modulus $Y$ in order to avoid the uncertain parameter "wall thickness" $d$ used by some authors. When considering flexural deformations of a nanotube (within the string approximation) in terms of the Young modulus, one should work with $Y d^{3}$, but it is evident that we can always switch between two pairs of independent parameters (e.g., from $Y$ and $d$ to $k$ and $\gamma$, where $\gamma$ denotes some flexural characteristic).

\section{Axial Stiffness of SWCNTs}

Since the investigation of the stiffness (or the Young modulus) of SWCNTs is not the main objective of this work, we will describe it briefly, by presenting, without derivation, only some formulas most important for our purposes. The continuum approximation for nanotubes used in this paper is obviously not exact for such nanostructures, but it is computationally simple and, in the case of small deformations, gives the appropriate value of stiffness (or Young modulus) without fitting parameters, as compared with other works. If needed, one can easily replace it with a more precise model using the same following expressions for the van der Waals interaction and stiffness.

In the simplest case, the axial stiffness of a cylindric shell (such as a nanotube) with surface density $m_{0} \tau\left(m_{0}\right.$ is the mass of each atom, and $\tau$ is their quantity per unit area) is defined by the expression

$k(R, L)=2 \pi m_{0} \tau c^{2} \frac{R}{L}=\alpha \frac{R}{L}$,

where $R$ and $L$ are the shell radius and length, $c$ is the longitudinal sound velocity, and $\alpha$ is the constant parameter for graphene-based structures. Certainly, the previous expression is proper for nanotubes of different radii only if shell properties are not radius-dependent. In the case of nanotubes with extremely small radii $\left(R \sim d_{0}\right.$, where $d_{0}=0.34 \mathrm{~nm}$ is the distance between graphitic planes conditioned by the van der Waals interaction), the re-hybridization of atomic orbitals leads to perceptible changes of SWCNT's mechanical properties (the raising of the effective Young modulus is observed in the quantum dynamics simulations for SWCNTs with $R<6$ $\mathrm{nm}[24,25])$, but such changes may be ignored for tubes with radii more than one nanometer.

The sound velocity $c$ may be obtained from microscopic models of nanotube (or graphene) as a velocity of acoustic phonons. Further, we will use the value $c=18.4 \mathrm{~km} / \mathrm{s}[26]$, which leads to $\alpha \approx 1632 \mathrm{~kg} \cdot \mathrm{s}^{-2}$. If necessary, the expressions for the effective Young modulus and Poisson's ratio can be also derived by comparing the equations of motion from both the microscopic and continuum models.

By (1), one can calculate the idealized Young modulus of SWCNT as

$Y=k \frac{L}{S}=\alpha \frac{R}{S}=\alpha \frac{R}{2 \pi R d} \approx 0.73 \mathrm{TPa}$,

where $S$ is the effective surface of the nanotube cross section, and the commonly accepted value of the "wall thickness" $d=d_{0}$ is used. On the other hand, the experimentally measurable effective Young modulus of a macroscopic bundle of SWCNTs depends not on the effective surface of its cross section, but on the total cross section surface of the bundle $S_{b} \approx N \pi\left(R+d_{0} / 2\right)^{2}$ (where $N$ is the number of tubes in the bundle, and $R$ is their radius):

$Y_{\mathrm{b}}=N k \frac{L}{S_{\mathrm{b}}}=N \alpha \frac{R}{S_{\mathrm{b}}}=\left.\alpha \frac{R}{\pi\left(R+d_{0} / 2\right)^{2}}\right|_{R \gg d_{0}} \approx \frac{\alpha}{\pi} \frac{1}{R}$.

One can see that the effective Young modulus of such a bundle should be inversely proportional to the average radius of nanotubes. 


\section{Van der Waals Intershell Interaction}

The continuum approximation to the van der Waals intershell interaction in MWCNTs and its applications were thoroughly studied in [27-30] in good agreement with the experiments [31] and the results of numerical simulations [32, 33].

Within the continuum approximation, the van der Waals intershell interaction energy of double-walled carbon nanotubes (DWCNTs) depends only on the radii $\left(r_{1}, r_{2}\right)$ and the lengths $\left(L_{1}, L_{2}\right)$ of shells (Fig. 2). In terms of the hypergeometric functions, it can be expressed as follows [30] (assuming that $L_{1} \geq L_{2}$ ):

$U_{0}\left(R_{1}, L_{1}, R_{2}, L_{2}\right)=\frac{3}{2} \pi^{3} \tau^{2} R_{1} R_{2} L_{2} \times$

$\times\left(\frac{21}{32} \gamma_{12} \frac{\Phi\left(\frac{11}{2}, R_{1}, R_{2}\right)}{\left(R_{1}+R_{2}\right)^{11}}-\gamma_{6} \frac{\Phi\left(\frac{5}{2}, R_{1}, R_{2}\right)}{\left(R_{1}+R_{2}\right)^{5}}\right)$

where $\gamma_{6}=2.43 \times 10^{-24} \mathrm{~J} \cdot \mathrm{nm}^{6}$ and $\gamma_{12}=3.859 \times$ $10^{-27} \mathrm{~J} \cdot \mathrm{nm}^{12}$ are the attractive and repulsive constants of the Lennard-Jones potential [27], $\tau$ is the surface density of carbon atoms, and

$\Phi\left(J, R_{1}, R_{2}\right):={ }_{2} \mathrm{~F}_{1}\left(\frac{1}{2}, J, 1, \frac{4 R_{1} R_{2}}{\left(R_{1}+R_{2}\right)^{2}}\right)=$

$$
=\frac{\left(R_{1}+R_{2}\right)^{2 J}}{2 \pi} \int_{-\pi}^{\pi} \frac{d \theta}{\left(R_{1}^{2}+R_{2}^{2}-2 R_{1} R_{2} \cos \theta\right)^{J}} .
$$

For the unstrained graphene (or a nanotube), $\tau=\tau_{0}=$ $\frac{4}{3 \sqrt{3} b^{2}}=38.2 \mathrm{~nm}^{-2}(b=0.142 \mathrm{~nm})$.

The length and the radius of a nanotube under tension take the values $l=L_{0}(1+\varepsilon)$ and $r=R_{0}(1-\nu \varepsilon)$, where $\varepsilon$ is the nanotube specific elongation, $\nu=0.17$ [34-36] is Poisson's ratio of graphene, and $L_{0}$ and $R_{0}$ are the length and the radius of the unstrained nanotube. In this case, the nanotube surface $S$ and the surface density of atoms change, correspondingly:

$S_{j}=2 \pi R_{j} L_{j}\left(1-\nu \varepsilon_{j}\right)\left(1+\varepsilon_{j}\right)$

$\tau_{j}=\frac{\tau_{0}}{\left(1+\varepsilon_{j}\right)\left(1-\nu \varepsilon_{j}\right)}$.

The interaction energy (2) in the case of strained shells ( $\varepsilon_{1}$ and $\varepsilon_{2}$, respectively) takes the form

$$
\begin{aligned}
& U\left(R_{1}, L_{1}, \varepsilon_{1}, R_{2}, L_{2}, \varepsilon_{2}\right)=\frac{3}{2} \pi^{3} \tau_{1} \tau_{2} r_{1} r_{2} l_{2}\left(\frac{21}{32} \gamma_{12} \frac{\Phi\left(\frac{11}{2}, r_{1}, r_{2}\right)}{\left(r_{1}+r_{2}\right)^{11}}-\gamma_{6} \frac{\Phi\left(\frac{5}{2}, r_{1}, r_{2}\right)}{\left(r_{1}+r_{2}\right)^{5}}\right)= \\
& =\frac{3}{2} \frac{\pi^{3} \tau_{0}^{2}}{1+\varepsilon_{1}} R_{1} R_{2} L_{2}\left(\frac{21}{32} \gamma_{12} \frac{\Phi\left(\frac{11}{2}, R_{1}\left(1-\nu \varepsilon_{1}\right), R_{2}\left(1-\nu \varepsilon_{2}\right)\right)}{\left(R_{1}\left(1-\nu \varepsilon_{1}\right)+R_{2}\left(1-\nu \varepsilon_{2}\right)\right)^{11}}-\gamma_{6} \frac{\Phi\left(\frac{5}{2}, R_{1}\left(1-\nu \varepsilon_{1}\right), R_{2}\left(1-\nu \varepsilon_{2}\right)\right)}{\left(R_{1}\left(1-\nu \varepsilon_{1}\right)+R_{2}\left(1-\nu \varepsilon_{2}\right)\right)^{5}}\right) .
\end{aligned}
$$

By $U_{\mathrm{W}}$, we denote the van der Waals deformation energy that is the contribution of the intershell interaction into the total deformation energy of a DWCNT:

$$
\begin{aligned}
& \Delta U_{\mathrm{W}}\left(R_{1}, L_{1}, \varepsilon_{1}, R_{2}, L_{2}, \varepsilon_{2}\right):= \\
& :=U\left(R_{1}, L_{1}, \varepsilon_{1}, R_{2}, L_{2}, \varepsilon_{2}\right)-U_{0}\left(R_{1}, L_{1}, R_{2}, L_{2}\right) .
\end{aligned}
$$

\section{Axial Stiffness of DWCNTs and MWCNTs}

The total deformation energy of DWCNT consists of the deformation energies of both shells and the additional (to that of the unstrained state) intershell interaction energy:

$E\left(\varepsilon_{1}, \varepsilon_{2}, R_{1}, R_{2}, L_{1}, L_{2}\right)=$

$$
\begin{aligned}
& =\frac{k_{1} \Delta L_{1}^{2}}{2}+\frac{k_{2} \Delta L_{2}^{2}}{2}+\Delta U_{\mathrm{W}}\left(R_{1}, L_{1}, \varepsilon_{1}, R_{2}, L_{2}, \varepsilon_{2}\right)= \\
& =\frac{\alpha}{2}\left(R_{1} L_{1} \varepsilon_{1}^{2}+R_{2} L_{2} \varepsilon_{2}^{2}\right)+\Delta U_{\mathrm{W}}\left(R_{1}, L_{1}, \varepsilon_{1}, R_{2}, L_{2}, \varepsilon_{2}\right) .
\end{aligned}
$$

If both DWCNT shells are of equal length $\left(L_{1}=L_{2}=L\right)$, its total deformation energy will be linear in $L$, and the relative deformation of the inner shell will depend only on that of the outer shell and the radii of shells.

We assume that the external force acts only on the outer shell and, as a result, the DWCNT axial stiffness should be introduced as

$$
k_{\mathrm{DW}}\left(\varepsilon_{1}\right)=\left.\frac{1}{L_{1}^{2}} \frac{\partial^{2} E}{\partial \varepsilon_{1}^{2}}\right|_{E=\min E\left(\ldots, \varepsilon_{2}, \ldots\right)}
$$




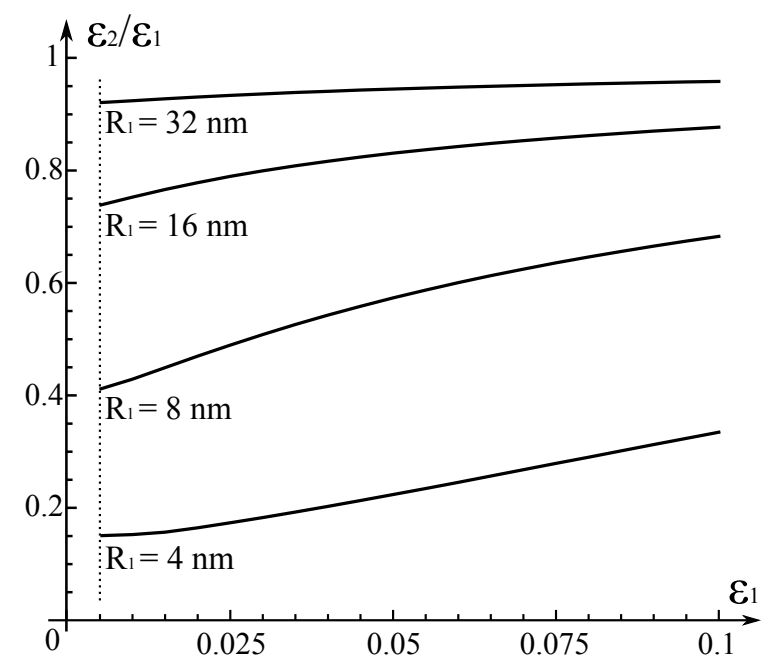

Fig. 3. Dependence between the relative deformations ( $\varepsilon_{1}$ and $\varepsilon_{2}$, correspondingly) of the outer and inner shells of different radii with unstrained intershell distance $d_{0}$ for DWCNTs. For very small $\varepsilon_{1}$, the DWCNT deformation is determined by its actual unstrained intershell distance, which is not likely to be equal to the energetically optimal distance $d_{0}$ due to the nanotube's radius discrete nature

Obviously, $\varepsilon_{2}<\varepsilon_{1}$, when $R_{1} \nu \varepsilon_{1}<d_{0}$, and, for a fixed value of $\varepsilon_{1}, \varepsilon_{2}$ will increase strongly with the DWCNT radius (Fig. 3 ).

Like that of DWCNT, the total deformation energy of $N$-walled MWCNT is determined by the expression

$E(\epsilon, R, L, N)=\frac{\alpha}{2} \sum_{i=1}^{N} R_{i} L_{i} \varepsilon_{i}^{2}+$

$+\sum_{i=1}^{N-1} \Delta U_{\mathrm{W}}\left(R_{i}, L_{i}, \varepsilon_{i}, R_{i+1}, L_{i+1}, \varepsilon_{i+1}\right)$,

where $\epsilon=\left(\varepsilon_{1}, \ldots, \varepsilon_{N}\right), \quad R=\left(R_{1}, \ldots, R_{N}\right)$ and $L=$ $\left(L_{1}, \ldots, L_{N}\right)$.

The axial stiffness in this case is defined as

$$
\begin{aligned}
& k_{\mathrm{MW}}\left(\varepsilon_{1}, R, L, N\right)= \\
& =\left.\frac{1}{L_{1}^{2}} \frac{\partial^{2} E\left(\epsilon_{\min }, R, L, N\right)}{\partial \varepsilon_{1}^{2}}\right|_{E\left(\epsilon_{\min }, \ldots\right)=\min _{\varepsilon_{2}, \ldots, \varepsilon_{N}} E(\epsilon, R, L, N)},
\end{aligned}
$$

where $\epsilon_{\min }$ is such a set of deformations of shells that, under a certain external tension, the MWCNT's total deformation energy takes its minimum value.

Unlike DWCNT, all but the innermost shells of MWCNT have the following neighbor, which hampers shell's deformation as compared with the case of

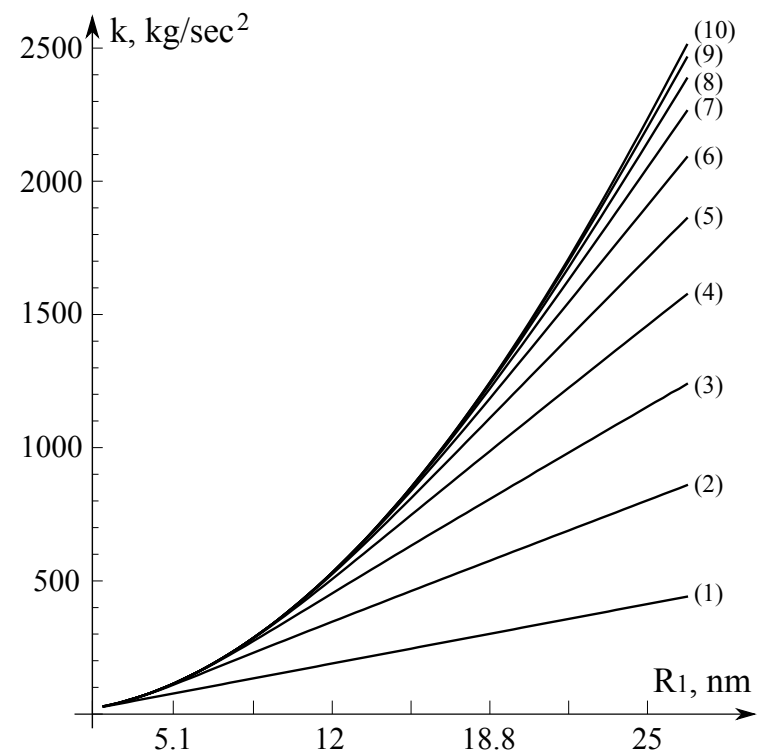

Fig. 4. Dependence of the MWCNT stiffness on the tube external radius $R_{1}$ and the number of its shells (in brackets) for $\varepsilon_{1}=0.05$ and $L=100 \mathrm{~nm}$. The asymptotic value of the number of shells involved into a deformation is about 15 even for the extremely large MWCNTs (for tubes with $R<10 \mathrm{~nm}$, only four shells are actually involved)

DWNCT, so that the relative deformation of inner shells $\varepsilon_{i}$ decreases rapidly with $i$. As a result, the actual axial stiffness of MWCNT grows with the number of shells much slower than its "ideal" stiffness $k_{\text {ideal }}=\sum k\left(R_{i}, L_{i}\right)$. Actually for MWCNTs with the external radius $R \leq 10$ $\mathrm{nm}$ and any number of shells under strain with $\varepsilon_{1} \lesssim 0.05$, only four external shells contribute to the total stiffness, and this number grows slowly up to $\approx 10$ for the nanotubes with $R>25 \mathrm{~nm}$ (Fig. 4).

For $N$-walled MWCNTs with external radii more than $3 \mathrm{~nm}$ (assuming that $N$ is greater than the number of shells actually involved into a deformation), the stiffness can be fitted by the following expression with an accuracy of $1-3$ per cents (for $0<\varepsilon_{1}<0.1$ ):

$$
\begin{aligned}
& k(R, L, \varepsilon)=\frac{10^{-7}}{L} \exp \left[2.3\left(\frac{R-d_{0}}{d_{0}}\right)^{0.267}\right] \times \\
& \times\left(1+\varepsilon\left[26.2-44\left(\frac{d_{0}}{R}\right)^{0.276}\right]\right) .
\end{aligned}
$$

\section{Discussion}

The analysis of the axial stiffness of ideal MWCNTs based on the van der Waals intershell interaction shows 
that only several external shells of MWCNT contribute to its total stiffness under a load imposed only on the external shell. The number of contributing shells is, in fact, less than 5 for nanotubes with $R \lesssim 10 \mathrm{~nm}$ and never exceeds 15 even for extremely thick nanotubes (Fig. 4). As a result, the MWCNT actual stiffness can be several times lower than its "ideal" stiffness, which is obtained under the assumption that all shells are loaded evenly. This fact should be taken into account, while MWCNTbased towlines, cables, and armoring elements are constructed.

Contrary to SWCNTs, which are, at least for small elongations, subordinated to the Hooke law $F=$ $k \varepsilon L, \quad k=$ const, the stiffness of MWCNTs depends linearly, even for rather weak loads, on the tube elongation $(k \sim \varepsilon)$ as a result of the load-induced gradual involvement of inner shells.

All calculations presented here in support of our assertion should be performed for the particular values of Poisson's ratio and sound velocity, which are (in the case of ideal lattice) uniquely determined only by the lattice structure and interatomic force constants. However up to now, there is a large scatter of the values of Poisson's ratio obtained by different authors $(\nu=0.14-0.19$ [35], $\nu=0.17-0.22[36], \nu=0.19[3,37], \nu=0.19-0.22$ [38], $\nu=0.20-0.23$ [39], $\nu=0.25-0.27$ [40], $\nu=0.27-0.28$ [19]). In most cases, $\nu \in 0.16-0.3$. Here, we used the value $\nu=0.17$, which is the mean value of Poisson's ratio for finite graphene sheets of various sizes [36] and chiral SWCNTs [36]. It is also close to the corresponding magnitude along the basal plane in graphite, $\nu=0.16$ [34].

In view of the existing scattering of data, we have looked how the calculated MWCNT stiffness depends on the used values of Poisson's ratio and sound velocity. It is clear that, as Poisson's ratio increases, the strain transmission from the outermost shell into the depth of the tube raises, which leads to higher values of nanotube stiffness. However even for $\nu=0.3$ (which exceeds most of its theoretical and experimental estimates for SWCNTs), it appears that only $12-15$ external shells contribute to $k$ even for MWCNTs with $R \geq 25 \mathrm{~nm}$ (with more than five dozens of shells) at subcritical strains $(\varepsilon \gtrsim 0.05)$. In other words, despite the fact that the actual stiffness of MWCNTs grows almost linearly with Poisson's ratio of shells, getting closer to the "ideal" stiffness value, the latter remains, nevertheless, many times higher. (The values of axial stiffness for varying values of Poisson's ratio can be found with an accuracy of several per cents by the interpolating formula $\left.k(\nu) \approx k\left(\nu_{0}\right)\left(1+\frac{17}{20} \frac{\nu-\nu_{0}}{\nu_{0}}\right)\right)$.
The sound velocity actually depends on the quality of shell's lattice and is connected with the stiffness of each shell and the "ideal" stiffness of a MWCNT by the relation $k \sim c^{2}$. It appears that the sound velocity and the MWCNT actual stiffness are linearly dependent in the interval $c=17000-23000 \mathrm{~km} / \mathrm{s}$ as a consequence of the weakening of inner shells strains due to the preferred accumulation of the van der Waals interaction energy in subsurface shells. So, if $c=18.4 \mathrm{~km} / \mathrm{s}$ used here is underestimated, the number of shells actually contributing to the MWCNT stiffness would be even smaller than that indicated above.

Note that the stiffness of perfect MWCNTs is perceptibly higher than that of MWCNTs with a rather low defect concentration [41], but their ratios to the corresponding "ideal" values are in the opposite relation (i.e., the actual and "ideal" rigidities would be most close in values in the case of pretty defect MWCNTs).

It should be noted also that some of MWCNT's inner shells can be segmented. In accordance to our analysis, such situations do not affect substantially the axial stiffness in all cases where the cumulative length of a "broken" shell is close to the length of its neighbors, and the gaps between parts of that shell are about the range of van der Waals interaction $(\sim 1 \mathrm{~nm})$. In other words, the elastic properties of MWCNTs are resistant to the fracture and a minor damage of some of its inner shells.

In the case where the $i$-th shell $(i>1)$ appears to be sufficiently shorter than the neighboring shells, the MWCNT can be considered as consistent of two parts placed in series with different numbers of walls and, as a result, different rigidities (the first part of the length $L_{1}-L_{i}$ is the $(i-1)$-walled MWCNT and the second part of the length $L_{i}$ is the $n$-walled MWCNT). The effective stiffness for such a series is $k=\frac{2 k_{1} k_{2}}{k_{1}+k_{2}}$, where $k_{1}$ and $k_{2}$ are determined by (7).

It is worth mentioning that it follows from the above analysis that the described effect of stiffness saturation does not depend on the temperature due to the very small value of SWCNT radial thermal expansion coefficient $\left(\sim 10^{-6} \mathrm{~K}^{-1}\right.$ at $\left.T \sim 300 \mathrm{~K}\right)[42,43]$ and the weak temperature dependence of sound velocities $\left(\sim 10^{-5} \mathrm{~K}^{-1}\right.$ at $\left.T \sim 300 \mathrm{~K}\right)$ [42].

Summing up, we can say that, for applications where the highest possible axial stiffness of a single MWCNT or nanotube bundle is needed, the thin 4-5-walled MWCNTs $(R \lesssim 2 \mathrm{~nm})$ are quite sufficient.

The author is grateful to Prof. Vadim Adamyan for discussions and remarks. The work was supported by 
the Ministry of Education and Science of Ukraine, Grant \#0109U000929.

1. R.S. Ruoff and D.C. Lorents, Carbon 33, 925 (1995).

2. S. Govindjee and J.L. Sackman, Solid State Commun. 110, 227 (1999).

3. B.I. Yakobson and Ph. Avouris, in Mechanical Properties of Carbon Nanotubes, edited by M.S. Dresselhaus, G. Dresselhaus, and Ph. Avouris, (Springer, Heidelberg, 2001), Topics in Applied Physics 80, 287.

4. B.I. Yakobson, C.J. Brabec, and J. Bernholc, Phys. Rev. Lett. 76, 2511 (1996).

5. M.F. Yu, O. Lourie, M.J. Dyer, K. Moloni, T.F. Kelly, and R.S. Ruoff, Science 287, 637 (2000).

6. S. Iijima, C. Brabec, A. Maiti, and J. Bernholc, J. Chem. Phys. 104, 2089 (1996).

7. D.A. Walters, L.M. Ericson, M.J. Casavant, J. Liu, D.T. Colbert, K.A. Smith, and R.E. Smalley, Appl. Phys. Lett. 74, 3803 (1999).

8. M.F. Yu, B.S. Files, S. Arepalli, and R.S. Ruoff, Phys. Rev. Lett. 84, 5552 (2000).

9. T.W. Tombler, C. Zhou, J. Kong, H. Dai, L. Liu, C.S. Jayanthi, M. Tang, and S.Y. Wu, Nature 405, 769 (2000).

10. M.M.J. Treacy, T.W. Ebbesen, and J.M. Gibson, Nature 381, 678 (1996).

11. A. Krishnan, E. Dujardin, T.W. Ebbesen, P.N. Yianilos, and M.M.J. Treacy, Phys. Rev. B 58, 14013 (1998).

12. E.W. Wong, P.E. Sheehan, and C.M. Lieber, Science 277, 1971 (1997).

13. J.P. Salvetat, G.A. D. Briggs, J.M. Bonard, R.R. Bacsa, A.J. Kulik, T. Stöckli, N.A. Burnham, and L. Forró, Phys. Rev. Lett. 82, 944 (1999).

14. B.G. Demczyk, Y.M. Wang, J. Cumings, M. Hetman, W. Han, A. Zettl, and R.O. Ritchie, Mater. Sci. Eng. A 334, 173 (2002).

15. Z.W. Pan, S.S. Xie, L. Lu, B.H. Chang, L.F. Sun, W.Y. Zhou, G. Wang, and D.L. Zhang, Appl. Phys. Lett. 74, 3152 (1999).

16. P. Zhang, Y. Huang, P.H. Geubelle, P.A. Klein, and K.C. Hwang, J. Solids Struct. 39, 3893 (2002).

17. Y. Wu, M. Huang, F. Wang, X.M. Henry Huang, S. Rosenblatt, L. Huang, H. Yan, S.P. O'Brien, J. Hone, and T.F. Heinz, Nano Lett. 8, 4158 (2008).

18. Z. Tu and Z. Ou-Yang, Phys. Rev. B 65, 233407 (2002).

19. J.P. Lu, Phys. Rev. Lett. 79, 1297 (1997).

20. P. Poncharal, Z.L. Wang, D. Ugarte, and W.A. de Heer, Science 283, 1513 (1999).

21. N. Yao and V. Lordi, J. Appl. Phys. 84, 1939 (1998).
22. Z. Xin, Z. Jianjun, and O.-Y. Zhong-can, Phys. Rev. B 62, 13692 (2000).

23. C. Li and T.W. Chou, Composit. Sci. Techn. 631517 (2003).

24. J.-Y. Hsieh, J.-M. Lu, M.-Y. Huang, and C.-C. Hwang, Nanotechn. 17, 3920 (2006).

25. Z. Peralta-Inga, S. Boyd, J.S. Murray, C.J. O'Connor, and P. Politzer, Struct. Chem. 14, 431 (2003).

26. V. Adamyan and V. Zavalniuk, J.Phys.: Condens. Matter 23, 015402 (2010).

27. L.A. Girifalco, M. Hodak, and R.S. Lee, Phys. Rev. B 62, 013104 (2000).

28. D. Baowan and J.M. Hill, Z. angew. Math. Phys. 58, 857 (2007).

29. D. Baowan, N. Thamwattana, and J.M. Hill, Commun. Nonlin. Sci. Numer. Simul. 13, 1431 (2008).

30. V. Zavalniuk and S. Marchenko, Low Temp. Phys. 37 337 (2011).

31. J. Cumings and A. Zettl, Science 289602 (2000).

32. J.L. Rivera, C. McCabe, and P.T. Cummings, Nanotechn. 16, 186 (2005).

33. S.B. Legoas, V.R. Coluci, S.F. Braga, P.Z. Coura, S.O. Dantas, and D.S. Galvao, Nanotechn. 15, 184 (2004).

34. O.L. Blakslee, D.G. Proctor, E.J. Seldin, G.B. Spence, and T. Weng, J. Appl. Phys. 41, 3373 (1970).

35. D. Sánchez-Portal, E. Artacho, J.M. Soler, A. Rubio, and P. Ordejón, Phys.Rev. B 59, 12678 (1999).

36. J.-W. Jiang, J.-S. Wang, and B. Li, Phys.Rev. B 80, 113405 (2009).

37. B.I. Yakobson, C.J. Brabec, and J. Bernholc, Phys. Rev. Lett. 76, 2511 (1996).

38. A. Sears and R.C. Batra, Phys. Rev. B 69, 235406 (2004).

39. V.N. Popov, V.E. Van Doren, and M. Balkanski, Phys. Rev. B 61, 3078 (2000).

40. Y.Jin and F.G. Yuan, Composit. Sci. Techn. 63, 1507 (2003).

41. J.P. Salvetat, A.J. Kulik, J.M. Bonard, G.A.D. Briggs, T. Stöckli, K. Méténier, S. Bonnamy, F. Béguin, N.A. Burnham, and L. Forró, Adv. Mater. 11, 161 (1999).

42. N.R. Raravikar, P. Keblinski, A.M. Rao, M.S. Dresselhaus, L.S. Schadler, and P.M. Ajayan, Phys. Rev. B 66, 235424 (2002).

43. A.V. Dolbin, V.B. Esel'son, V.G. Gavrilko, V.G. Manzhelii, N.A. Vinnikov, and S.N. Popov, Fiz. Nizk. Temp. 34, 860 (2008).

Received 12.03.2012 
ЗАЛЕЖНІСТЬ ПОЗДОВЖНЬОЇ

ЖОРСТКОСТІ БАГАТОСТІНКОВИХ

ВУГЛЕЦЕВИХ НАНОТРУБОК ВІД КІЛЬКОСТІ СТІНОК

В. Завалънюк

$\mathrm{P}$ е $з$ ю м е

Вивчено залежність поздовжньої жорсткості багатостінкових вуглецевих нанотрубок в залежності від числа стінок та їх геометричних параметрів. Показано, що результуюча жорс- ткість всієї нанотрубки визначається лише декількома зовнішніми стінками (як правило, 3-5 та досягаючи 15 в разі сильно деформованих нанотрубок великого радіуса), що добре співвідноситься з експериментальними значеннями модуля Юнга для багатостінкових нанотрубок. Подібна поведінка є наслідком міжстінкової ван-дер-ваальсівської взаємодії. Також наводиться проста інтерполяційна формула, що пов'язує граничну поздовжню жорсткість ідеальної багатостінкової нанотрубки при конкретному відносному подовженні з їі зовнішнім діаметром та довжиною. 